\title{
Under the Background of "New Normal", Research on Constructing the Productive and Technical Preparation System Based on Lean Thinking for Locomotives -Take M Company as an Example
}

\author{
Ming $\mathrm{Ma}^{*}$ and $\mathrm{Tao} \mathrm{Lu}$ \\ School of Economy and Management, Nanjing University of Science and Technology University, Nanjing, China \\ Corresponding Email: maming163@126.com
}

\begin{abstract}
This paper introduces the lean production theory and the application of lean production technology preparation system in related enterprises, put forward own views on a series of problems existing in the preparation of M company's production technology. Aiming at these problems, this paper combined with the practical application of lean thinking to the traditional production technology for system innovation and optimization, builds a clear $\mathrm{M}$ simulated production line concept, principles and framework, basically puts forward a complete set of methods and measures to construct the core technology of lean production system for part of the simulated production line.
\end{abstract}

\section{Introduction}

Under the background of "new normal", China's economy from high-speed growth to medium high speed, facing all kinds of users increasingly diversified, personalized, multi variety, small quantities of demand, production enterprise production technology preparation system flexibility is obviously insufficient, how to seize the opportunity of transformation and upgrading, become a new challenge in the face of various types of enterprises. $\mathrm{M}$ company is a locomotive manufacturing enterprise, in the long history of evolution and the process of production organization, has formed a set of relatively mature, fixed the new production of the locomotive production system. However, this set of system has been unable to fully adapt to the market demand for the production of new locomotives. Specifically, it mainly has the following four aspects of the problem: 1) production technology to prepare the elements is not comprehensive enough2) production technology preparation system flexibility is relatively short3) the preparation process of the production technology is poor4) the coordination of the functional departments in the preparation process is seriously insufficient.

In this paper, the use of Lean Thinking on the traditional production technology to prepare the system for innovation and optimization, clear M company based on lean thinking of the locomotive production technology preparation system construction strategy, methods and measures.

\section{Literature review}

The establishment of production technology preparation system based on lean thinking is the innovation practice of lean production mode, and its most important theoretical foundation lies in the research results of lean production. Lean production (Production Lean, referred to as LP) is an expert in the United States Massachusetts Institute of Technology Digital International Automotive Program Organization of Japan's TOYOTA on time production of JIT production mode of praise. James P. Womack and Daniel T. Jones increases lean production to a theoretical height [1].Art Smalley provides a good guide for the enterprise to use the balanced production method [2].Daniel T. Jones and James P. Womack promotes the lean supply to lean solutions, to achieve the value and wealth of the company and customers [3].M. E. Bayou and A.de Korin are based on previous studies put forward their own definition of lean production, the definition includes two dimensions of input and output in two aspects, namely the investment efficiency and effectiveness, tangible and intangible resources and cost, quality and service is the output of the final product. The research and practice of lean thinking in China is at the beginning of 1990s, Qi Ershi published a conference paper, gives the definition of lean production, and the grey theory is introduced to the analysis of the evaluation of the lean production area [4].Chen Lu in the "Journal of mechanical design and manufacturing engineering" published "the study 
on the production process optimization simulation of production line based on Simulation of rail vehicles, discusses the production line process design, process parameters and process route selection etc. [5].

\section{Based on lean thinking of $M$ company locomotive production technology preparation system composition strategy}

\subsection{The composition of locomotive production technology preparation system of $M$ company based on Lean Thinking}

The technology preparation system of locomotive production based on lean thinking consists of two parts, which are the simulation production line and the simulation distribution line, this paper only discusses the construction strategy of the simulation production line.

The simulation production line is the core component of the lean production technology preparation system, it refers to: Before the trial of the project node, recognition "three new"(New materials, new structures and new technologies),Through the "three off"(simulation, verification and coordination operations), to maximize the efficiency, economic and safety of the project trial production; To design and simulate the site work station, and to promote the preparation of the resources needed for the station before the start of construction; Through the simulation and verification of the trial production, reduce the abnormal production, shorten the trial cycle, so that mass production can enter the rhythm of production as soon as possible.

\subsection{The construction strategy of simulation production line}

The basic framework for the construction of the analog production line can be summarized as follows "Six stages, six contents, six elements".

The six stage refer to: Simulation planning, simulation preparation, simulation start, simulation deduction, simulation evaluation, simulation verification

The six contents refer to: The main contents of the construction of the analog production line, that is stage definition, division of labor, work content, input and output, operating points, the use of tools;

Six elements refer to: Six management factors of construction simulation production line, that is human, machine, material, method, ring, measurement

The division of responsibilities of the construction of each simulation production line is no longer detailed list.

\subsubsection{Simulation planning}

Simulation planning is the first stage of the whole production line construction project is simulated, in order to realize the simulation of production line construction and efficient operation of the target, the application of lean thinking and methods, process design, design and production of simulated production line implementation of the project. In the simulation planning stage, to do a good job in several aspects of the work: (1)Fully understand customer needs (2)The recognition of "three new" points(3) Preparation of simulation plans

\subsubsection{Simulation preparation}

Simulation is prepared by the further decomposition and refinement of the implementation plan of the simulated production line, from the production, technology, management and other aspects, the simulation of the simulation of the production line to the specific point of the specific arrangements for the process, it is the most substantial working stage of the whole simulation production line. (1)Clear six elements of the preparation requirements in order to stimulate the implementation of the preparation of simulation. (2) Define the task of each module. (3) input and output of the simulation preparation stage are shown in table 1 .

Table 1. The input and output of the simulation preparation stage.

\begin{tabular}{|c|c|c|c|}
\hline Department name & input & output & Receiving unit \\
\hline \multirow{2}{*}{ Process department } & Simulation program & Analog line work network plan & \multirow{2}{*}{$\begin{array}{c}\text { Various departments of the } \\
\text { project team }\end{array}$} \\
& Network plan map & Unit module task \\
\hline $\begin{array}{c}\text { Production } \\
\text { planning and } \\
\text { management } \\
\text { department }\end{array}$ & project plan & Pre-production plan & $\begin{array}{c}\text { Various departments of the } \\
\text { project team }\end{array}$ \\
\hline
\end{tabular}




\subsubsection{Simulation start}

The simulation starts according to the working network plan and the pre-production plan of the simulation production line, and the organization of each department is discussed and analyzed. In essence the simulation starts only as a landmark node of the whole simulation line. The input and output of the simulation start-up stage are shown in table 2.

Table 2. Simulation start stage of the input, output.

\begin{tabular}{|c|c|c|c|}
\hline Department name & input & output & Receiving unit \\
\hline Process department & $\begin{array}{c}\text { Analog line work network plan; } \\
\text { Unit module task }\end{array}$ & Analog start meeting minutes & $\begin{array}{c}\text { Various departments of } \\
\text { the project team }\end{array}$ \\
\hline
\end{tabular}

\subsubsection{Simulation deduction}

Simulation deduction is the simulation unit in accordance with the plan and responsible for the implementation of the scheme and the contents of six elements for each station on the spot inspection, through the passage of exercise, combing management ideas, found that the problem, the bottleneck and the implementation of the difficult process. Simulation deduction is a process of continuous implementation, verification, discovery and improvement, which is in line with the concept of the famous "Deming" management cycle in lean production, through the "PDCA" management cycle, so that the whole process of management level has been continuously improved. "PDCA" management cycle is shown in Figure 1.

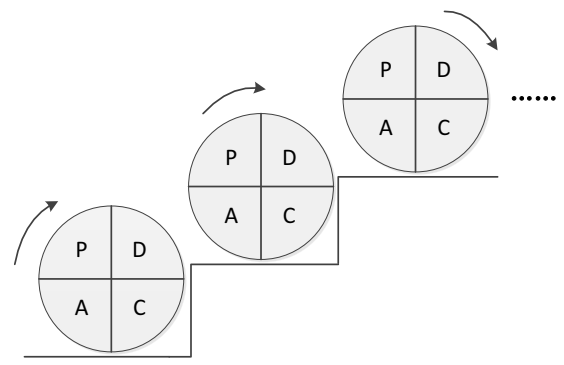

Fig. 1. "PDCA" management cycle diagram.

(1)Division of labor, that is, the Department of technology, manpower, equipment management, quality management, production planning and management department, procurement department, the Department of the ring, the logistics sector, manufacturing units and so on. (2)The contents of the work, the planning and implementation of node, process control, project inspection and issue report etc.. (3)Input and output content due to space constraints, is no longer listed.

\subsubsection{Simulation evaluation}

Simulation evaluation is to summarize the process of simulation, the risk assessment, analysis and rectification of all kinds of problems, and make the process of preparing for the simulation. In the simulation evaluation stage, the need to do a good job in two areas of focus. (1) Hold a meeting(2) Ready to start the "six elements"(3) Input and output content due to space constraints, is no longer listed.

\subsubsection{Simulation verification}

Simulation verification is the base station file manufacturing unit formed in the pre-construction line simulation and evaluation report, for trial according to production plan, and the problem will produce abnormal production of timely feedback to the relevant departments, and in the process of rectification after curing into standard process documents. (1) Work content formulation(2) The input and output of the simulation verification stage are shown in Table 3.

Table 3. Simulation verification stage of the input and output.

\begin{tabular}{|c|c|c|c|}
\hline Department name & input & output & Receiving unit \\
\hline $\begin{array}{c}\text { Production planning } \\
\text { and management } \\
\text { department }\end{array}$ & $\begin{array}{c}\text { Project contract, Simulation } \\
\text { program, Single start check }\end{array}$ & Trial production plan & $\begin{array}{c}\text { Manufacturing } \\
\text { unit }\end{array}$ \\
\hline
\end{tabular}




\begin{tabular}{|c|c|c|c|}
\hline Manufacturing unit & $\begin{array}{c}\text { Station file, } \\
\text { Trial production plan }\end{array}$ & $\begin{array}{l}\text { Field production line, Verification } \\
\text { feedback table }\end{array}$ & \\
\hline Process department & $\begin{array}{c}\text { Verification feedback table, } \\
\text { Problem improvement } \\
\text { program }\end{array}$ & $\begin{array}{l}\text { Validation report for analog line, } \\
\text { Standard process file }\end{array}$ & $\begin{array}{l}\text { Various } \\
\text { departments of } \\
\text { the project team }\end{array}$ \\
\hline Design Department & $\begin{array}{c}\text { Field production line, } \\
\text { Before the new verification } \\
\text { points }\end{array}$ & $\begin{array}{l}\text { Problem improvement program, } \\
\text { After verification three points }\end{array}$ & \\
\hline Other departments & $\begin{array}{l}\text { Station file, } \\
\text { Verification feedback table }\end{array}$ & $\begin{array}{l}\text { Problem to improve the program, the } \\
\text { six elements of the standard to verify } \\
\text { the standard document }\end{array}$ & \\
\hline
\end{tabular}

\section{Conclusions}

In this paper, a strong representative of the Q company as a case study, find that the existing production technology for system elements is not comprehensive, lack of flexibility and controllability during the functional departments of the poor, a serious shortage of coordination. On this basis, according to the relevant theory of enterprise production management and lean production, closely combined with the actual production and operation of Q company, puts forward the construction of Q company lean production technology of locomotive product preparation system based on strategy. Although, lean production technology of locomotive product preparation system although there are strong guidance on, but I have some limitations in the construction technology of lean production system for the theory of knowledge, there are a lot of work and details need to be sustained, in-depth study. Sincerely hope that there are more professional scholars and production management personnel in this field for more in-depth research, discussion and practice.

\section{Acknowledgment}

Nanjing University of Science and Technology, the Central University of basic scientific research business expenses special funds "Research on the main body position of the construction of scientific and technological innovation talents in Enterprises" (No. 30920140122009) ; Nanjing University of Science and Technology, the Central University of basic scientific research business expenses special funds "Research on efficiency evaluation of transportation industry based on network DEA" (No.30920130132009) ; Soft science research project of Jiangsu Province "Research on the reform of policy coordination management of Jiangsu science and technology innovation and Entrepreneurship Talent Policy" (BR2014099).

\section{References}

1. Womack, J.P. \& Jones, D.T. From lean production to the lean enterprise. Harvard Business Review 24, 38-46 (1996).

2. Smalley, A. Creating Level Pull. Lean Enterprise Institute (2004).

3. Jones, D.T. \& Womack, J.P. Lean Consumption. Harvard Business Review 83, 58-68 (2005).

4. Tian Qing, Zhou Gang \& Liu Haihong\& Er Shi Qi. Research on logistics system of TOYOTA production mode. in China mechanical engineering society material handling branch annual meeting 20-23 (2000).

5. Chen Lu \& Chu Weizhuo. Study on the optimization of the production process of the rail vehicle based on the simulated production line. Mechanical design and manufacturing engineering,61-66 (2015). 